\title{
CARACTERÍSTICAS gUIMICAS E SENSORIAIS DE CORTES COMERCIAIS DE CAPRINOS SRD E MESTIÇOS DE BÔER ${ }^{1}$
}

\author{
Marta Suely MADRUGA ${ }^{2, *}$, Narendra NARAIN ${ }^{3}$, Terezinha Fernandes DUARTE ${ }^{2}$, \\ Wandrick Hauss de SOUSA", Mércia de Sousa GALVÃO ${ }^{2}$, Maria Glória G. CUNHA ${ }^{4}$, Jorge Luiz F. RAMOS ${ }^{4}$
}

\begin{abstract}
RESUMO
Foram estudados o efeito dos fatores genótipos (F1 SRD x Bôer e SRD) e cortes comerciais (paleta, perna, lombo, costela e pescoço) na qualidade físico-química ( $\mathrm{pH}$, atividade de água), qualidade química (composição centesimal, colesterol, cálcio, fósforo e ferro) e qualidade sensorial (aparência, aroma caprino, aroma de carne assada, textura, maciez, sabor, suculência e qualidade total) da carne caprina. Os fatores genótipos e cortes comerciais influenciaram de forma significativa a composição química da carne caprina. A perna foi o corte que apresentou o maior valor nutricional, com alto teor de proteína e a baixa concentração de lipídeos. No entanto, os atributos sensoriais sofreram pouca influência destes fatores, observando-se uma tendência pela preferência, por parte dos provadores, pela carne dos caprinos da raça F1 - SRD x Bôer. A carne caprina, seja de animais mestiços de Bôer ou de animais SRD, apresentou-se como alimento de excelente valor nutricional, com baixos teores de gordura e elevados percentuais protéicos, associados às excelentes características sensoriais.

Palavras-chave: carne caprina, qualidade química, qualidade sensorial, cortes comerciais, genótipos.
\end{abstract}

\section{SUMMARY}

CHEMICAL AND SENSORIAL CHARACTERISTICS OF COMMERCIAL MEAT CUTS OF “MESTICOS” AND BOER GOATS. The effect of the factor genotypes (F1 - SRD x Bôer and SRD) and type of cuts (pallet, leg, loin, rib and neck) were studied on the physic-chemical (pH, water activity), chemical (proximate composition, cholesterol, calcium, phosphorus and iron contents) and sensory quality (appearance, goaty aroma, roasted meat aroma, texture, tenderness, flavour, juiciness, overall palatability) of goat meat. Both genotype and commercial cuts had significant influence $(p<0,05)$ on the chemical composition of the goat meat. The leg portion had the best nutritional value, presenting high protein and low lipid contents. However, the sensory parameter had low influence of them, the panel members had a preference for goat meat from F1 - SRD x Bôer animals. The goat meat either of F1 - SRD x Bôer or of SRD breeds was considered as a food of excellent nutritional quality, having low fat and high protein contents, along with excellent sensorial characteristics.

Keywords: goat meat, chemical quality, sensorial quality, commercial cuts, genotypes.

\section{1 - INTRODUÇÃO}

O rebanho de caprinos brasileiro é de mais de 9 milhões de cabeças, sendo que o Brasil é considerado o $18^{\circ}$ produtor mundial. A região Nordeste, por razões climáticas e socioeconômicas, participa com cerca de $93 \%$ do efetivo nacional [12]. No entanto, considerando a dimensão territorial brasileira e as condições edafoclimáticas favoráveis, nossos rebanhos ainda são inexpressivos.

O rebanho brasileiro de caprinos é constituído principalmente por animais denominados SRD (Sem Raça Definida), os quais são resultado do cruzamento da raça nativa conhecida como Crioulo com raças importadas [31]. Os rebanhos SRD são caracterizados pelo baixo peso e reduzida capacidade de produzir carne e leite, porém apresentam alta resistência às doenças e ao clima, mesmo quando submetidos a uma alimentação reduzida. Apenas recentemente se vem melhorando este rebanho, introduzindo-se raças com aptidão para

${ }^{1}$ Recebido para publicação em 09/08/2004. Aceito para publicação em 15/09/2005 (001388).

${ }^{2}$ Departamento de Tecnologia Química e de Alimentos (DTQA/CT). Universidade Federal da Paraíba (UFPB). Campus I. João Pessoa, CEP 58059-900, Paraíba.E-mail: msmadruga@uol.com.br.

${ }^{3}$ Departamento de Engenharia Química (DEQ/CCET). Universidade Federal de Sergipe (UFS). São Cristóvão, CEP 49100-000, Sergipe. E-mail: narendra@ufs.br.

${ }^{4}$ Empresa Estadual de Pesquisa Agropecuária da Paraíba (EMEPA-PB). Rua Eurípedes Tavares, 210, Tambiá. CEP 58013-290, João Pessoa-PB. E-mail: wandrick@emepa.org.br.

*A quem correspondência deve ser enviada. a produção de carne, a exemplo da raça Bôer, especializada em carne. Entre as raças exóticas predominantes no Brasil, para a produção de carne ou leite, sobressaem a Anglo-nubiana, Saanem e British Alpina.

A produtividade ou qualidade da carne caprina também é afetada pela falta de padronização dos cortes, má qualidade dos produtos, falta de canais adequados de comercialização, ausência de crédito e assistência técnica deficiente [5, 6, 34]. Além disso, vale ressaltar que outros fatores influem na produção e no consumo da carne caprina, estando estes diretamente ligados à qualidade, dentre os quais se citam a raça, a idade de abate, o sistema de produção, a castração etc [18].

O cruzamento industrial está se tornando uma prática constante nos sistemas de produção de caprinos de corte, uma vez que animais puros possuem preços elevados e os SRD apresentam baixo rendimento de carcaças. É possível obter destes cruzamentos maior velocidade de crescimento e melhor conformação e composição da carcaça. A eficiência deste processo depende das raças selecionadas, da individualidade dos animais e do nível nutricional dos mesmos [33].

O valor comercial da carne está baseado no seu grau de aceitabilidade pelos consumidores, o qual está diretamente correlacionado aos parâmetros de palatabilidade do produto. As características da carne que contribuem com a "palatabilidade" são aquelas agradáveis aos olhos, nariz e paladar, dentre as quais sobressaem os aspectos organolépticos de sabor ou 
"flavour" e de suculência. Ambas propriedades podem ser influenciadas por diversos fatores, os quais exercem forte influência na qualidade e na quantidade das gorduras. Nos últimos anos o interesse pela carne caprina tem crescido, em função também de suas propriedades nutricionais, pois apresenta baixos teores de colesterol, gordura saturada e calorias, quando comparada com as demais carnes vermelhas [16]. No entanto, a carne caprina possui sabor e odor característicos, que se acentuam em animais adultos [4, 21]. Dentre os parâmetros que apresentam influência direta na qualidade da carne de caprinos do Nordeste do Brasil, os químicos tem sido objeto de diversas pesquisas. Observase que os conhecimentos científicos relativos à composição centesimal, composição mineral, perfil de ácidos graxos e colesterol destas carnes, sob a influência dos fatores pré e pós-abate, estão registrados na literatura em revisão de MADRUGA [ 18] e ZAPATA et al. [38]. Os aspectos sensoriais também vêm ganhando destaque, principalmente no que diz respeito à correlação entre os atributos sensoriais e a composição química [23, 38].

MADRUGA [16] reportou que, ao se comparar os atributos sensoriais de carnes de caprinos de raça exótica aos de SRD, observou-se que o fator genótipo não influenciou os parâmetros de sabor, maciez, suculência e aroma característico e, desta forma, comprovou-se mais uma vez que os caprinos SRD, quando submetidos a um sistema de criação adequado, produzem carne de qualidade excelente, comparáveis ao Bôer.

Percebe-se também uma tendência no consumo da carne caprina in natura em seus cortes mais nobres, visto que apresentam características especiais, alcançando alto valor de mercado [27]. Desta maneira, verifica-se que cortes de segunda ou de animais velhos têm comercialização dificultada [6]. Neste contexto, é de fundamental importância a busca da melhoria da qualidade potencial do produto final, tornando-se necessário o estudo e o controle destes fatores no intuito de oferecer ao mercado consumidor produtos de qualidade a preços competitivos. O objetivo deste trabalho foi avaliar a influência de dois genótipos em diferentes cortes comerciais de carne caprina, através de estudos das características químicas e sensoriais.

\section{2 - MATERIAL E MÉTODOS}

\section{1 - Material}

O estudo foi realizado utilizando-se o tecido muscular de cinco cortes comerciais (paleta, perna, lombo, costela e pescoço) de meia carcaça de animais inteiros, sendo cinco do genótipo SRD (Sem Raça Definida) e cinco do genótipo mestiço (F1 - 1/8 Bôer + 1/8 SRD). Todos os caprinos foram terminados em regime de confinamento com alimentação constituída de 35\% de feno de maniçoba, $40 \%$ de milho, $24 \%$ de soja e $1 \%$ de mistura de sal mineral, tendo seus pesos controlados e a idade de abate de 228 dias. Os caprinos foram oriundos da Estação Experimental de Pendência, base física pertencente à Empresa Estadual de Pesquisa Agropecuária da Paraíba (EMEPA-PB).
Os animais a serem abatidos foram deixados em dieta hídrica por 24 horas e pesados antes do abate. Após a insensibilização, pelo método de atordoamento por concussão cerebral com marreta, procedeu-se à sangria, esfola e evisceração, mantendo-se as carcaças à temperatura ambiente por 6-8 horas, antes do armazenamento em câmara frigorífica a $2^{\circ} \mathrm{C}$ por 24 horas. Em seguida, procedeu-se a obtenção dos cortes comerciais, toalete dos cortes para remoção da gordura de cobertura em embalagem individual em sacos de polietileno sob vácuo e armazenamento em freezer a $-20^{\circ} \mathrm{C}$ até que as análises fossem realizadas.

\section{2 - Preparo das amostras}

Os cortes foram retirados do freezer e colocados sob refrigeração por 24 horas para o descongelamento, seguido de desossa e trituração em multiprocessador doméstico, procedendo-se então a subamostragem para as diferentes análises. Aproximadamente $400 \mathrm{~g}$ de tecido muscular de cada corte comercial foram utilizados para as análises.

\section{3 - Análises físico-químicas e químicas}

As análises físico-químicas (pH e AW) e químicas (umidade, cinza, lipídeos, proteínas, cálcio, ferro, fósforo e colesterol) foram realizadas utilizando-se 10 amostras com três repetições de cada corte avaliado (paleta, perna, lombo, costela e pescoço).

\subsection{1 - pH e AW}

A determinação da atividade de água foi realizada em aparelho Aqualab $\mathrm{CX}_{2}$ e o pH através de potenciômetro digital (Digimed PS2), segundo procedimentos do Instituto Adolfo Lutz [13].

\subsection{2 - Composição centesimal e colesterol}

Umidade, cinzas e proteína foram determinadas segundo a metodologia da AOAC [2]. As dosagens dos componentes lipídicos constaram de determinação de lipídeos [10] e de colesterol total [8].

\subsection{3 - Dosagem de minerais}

Os teores de ferro e fósforo foram determinados de acordo com a metodologia de RANGANNA [29] e o cálcio segundo o Instituto Adolfo Lutz [13].

\section{4 - Análise sensorial}

A análise sensorial foi realizada utilizando-se o teste da Escala Hedônica, com três repetições para cada tratamento, segundo AMARINE et al. [1] e LARMOND [14]. Porções de $200 \mathrm{~g}$ de carne caprina descongelada foram cortadas em cubos de $1 \mathrm{~cm}^{3}$ e cozidas em forno pré-aquecido a $200^{\circ} \mathrm{C}$ até que a temperatura interna da amostra atingisse $75^{\circ} \mathrm{C}$. Quatro cubos escolhidos ao acaso foram transferidos para um Bequer pré-aquecido, codificado e coberto com vidro de relógio, para evitar perda de voláteis. O Bequer contendo a 
amostra foi colocado em banho-maria, objetivando-se manter a temperatura da mesma na faixa de $65-70^{\circ} \mathrm{C}$ [21].

Uma equipe de 15 provadores semitreinados realizou as análises sensoriais. Cada atributo foi pontuado numa escala de 1 a 9, de tal forma que 1 referiu-se à condição menos favorável e 9 à mais favorável, em relação aos parâmetros sensoriais de aparência, odor caprino, odor de carne assada, textura, maciez, sabor, suculência e qualidade total. O formulário utilizado continha termos que variaram de muitíssimo bom a muitíssimo ruim; gostei muitíssimo a desgostei muitíssimo; extremamente intenso a extremamente fraco; extremamente macio a extremamente duro; extremamente seco a extremamente suculento.

\section{5 - Análise estatística}

Os dados obtidos nas análises físico-químicas, químicas e nos testes de avaliação sensorial foram submetidos à análise de variância obedecendo a um delineamento inteiramente casualizado com arranjo fatorial $5 \times 2$ (cinco cortes comercias e dois genótipos), com três repetições, utilizando-se o teste $\mathrm{F}$ para comparar os quadrados médios e determinar a significância dos efeitos dos fatores avaliados. A comparação entre as médias foi efetuada pelo teste de Tukey a 5\% de probabilidade [28]. Os dados foram analisados pelo programa estatístico Statistical Analysis System (SAS), versão 6.12 [32].

\section{3 - RESULTADOS E DISCUSSÃo}

A Tabela 1 apresenta os resultados obtidos nas análises físico-químicas e químicas dos cinco cortes comerciais de carne caprina dos dois genótipos. Foi observada interação entre os fatores genótipos e cortes comerciais para os teores de proteína, cálcio, ferro, fósforo e colesterol. O fator corte influenciou significativamente $(\mathrm{p}<0,05)$ no $\mathrm{pH}$, e nos conteúdos de umidade e gordura da carne dos animais estudados.

Considerando-se os cortes comerciais dos caprinos SRD, observou-se diferença significativa $(\mathrm{p}<0,05)$ entre o corte lombo $(5,96)$ e os demais cortes $(6,07$ a 6,24$)$. Na literatura pesquisada não foram encontrados valores de $\mathrm{pH}$ para diferentes cortes de ruminantes, no entanto MADRUGA [17] reportou que a carne caprina apresentou maior valor de pH final em comparação com outras carnes, com variação de 5,80 a 6, 99, levando a uma carne com coloração vermelho escuro bastante peculiar e de maior capacidade de retenção de água e, conseqüentemente, menores perdas

TABELA 1 - Características físico-químicas e químicas da carne in natura de cinco cortes comercias de caprinos SRD e mestiço (F1 - SRD x Bôer $)^{(1)}$

\begin{tabular}{|c|c|c|c|c|c|c|}
\hline \multirow{2}{*}{ Atributo } & \multirow{2}{*}{ Genótipo } & \multicolumn{5}{|c|}{ Corte comercial } \\
\hline & & Paleta & Perna & Lombo & Costela & Pescoço \\
\hline \multirow{2}{*}{$\mathrm{pH}$} & M. de Bôer & $6,06^{\mathrm{Aa}} \pm 0,02$ & $5,93^{\mathrm{Aa}} \pm 0,14$ & $6,03^{\mathrm{Aa}} \pm 0,14$ & $6,20^{A a} \pm 0,70$ & $6,17^{\mathrm{Aa}} \pm 0,11$ \\
\hline & SRD & $6,19^{A a} \pm 0,04$ & $6,21^{\mathrm{Aa}} \pm 0,15$ & $5,96^{\mathrm{Ab}} \pm 0,14$ & $6,07^{\mathrm{Aa}} \pm 0,14$ & $6,24^{\mathrm{Aa}} \pm 0,01$ \\
\hline \multirow{2}{*}{ AW } & M. de Bôer & $0,994^{\mathrm{Aa}} \pm 0,001$ & $0,990^{\mathrm{A} a} \pm 0,007$ & $0,990^{\mathrm{Aa}} \pm 0,004$ & $0,989^{\mathrm{Aa}} \pm 0,003$ & $0,995^{\mathrm{Aa}} \pm 0,001$ \\
\hline & SRD & $0,993^{\mathrm{Aa}} \pm 0,001$ & $0,994^{\mathrm{A} a} \pm 0,002$ & $0,995^{\mathrm{Aa}} \pm 0,002$ & $0,995^{\mathrm{Aa}} \pm 0,002$ & $0,997^{\mathrm{Aa}} \pm 0,001$ \\
\hline \multirow{2}{*}{$\begin{array}{l}\text { Umidade } \\
(\mathrm{g} / 100 \mathrm{~g})\end{array}$} & M. de Bôer & $71,88^{\mathrm{Aa}} \pm 3,08$ & $75,13^{A \mathrm{~b}} \pm 0,97$ & $71,03^{\mathrm{Aa}} \pm 1,37$ & $71,99^{\mathrm{Aa}} \pm 1,93$ & $71,73^{\mathrm{Aa}} \pm 0,49$ \\
\hline & SRD & $74,78^{\mathrm{Aab}} \pm 2,87$ & $75,82^{\mathrm{A} a} \pm 0,94$ & $72,55^{\mathrm{Aab}} \pm 1,57$ & $70,52^{\mathrm{Ab}} \pm 1,98$ & $72,97^{\mathrm{Aab}} \pm 2,71$ \\
\hline \multirow{2}{*}{$\begin{array}{l}\text { Cinzas } \\
(\mathrm{g} / 100 \mathrm{~g})\end{array}$} & M. de Bôer & $1,09^{A a} \pm 0,05$ & $0,98^{\mathrm{Aa}} \pm 0,05$ & $1,02^{\mathrm{Aa}} \pm 0,17$ & $1,08^{\mathrm{Aa}} \pm 0,13$ & $1,06^{\mathrm{Aa}} \pm 0,03$ \\
\hline & SRD & $1,04^{\mathrm{Aa}} \pm 0,09$ & $1,14^{\mathrm{Aa}} \pm 0,04$ & $1,04^{\mathrm{Aa}} \pm 0,06$ & $1,09^{A a} \pm 0,03$ & $1,06^{\mathrm{Aa}} \pm 0,03$ \\
\hline \multirow{2}{*}{$\begin{array}{l}\text { Lipídeos } \\
\text { (g/100 g) }\end{array}$} & M. de Bôer & $4,98^{\mathrm{Ab}} \pm 1,35$ & $2,52^{\mathrm{AC}} \pm 0,05$ & $7,52^{\mathrm{Aa}} \pm 0,71$ & $6,56^{\mathrm{Aab}} \pm 3,24$ & $6,52^{\mathrm{Aab}} \pm 0,26$ \\
\hline & SRD & $4,39^{A a} \pm 1,75$ & $2,86^{\mathrm{Aa}} \pm 0,46$ & $4,9^{\mathrm{Aa}} \pm 2,68$ & $6,27^{\mathrm{Ab}} \pm 1,28$ & $3,44^{\mathrm{Aa}} \pm 2,33$ \\
\hline \multirow{2}{*}{$\begin{array}{l}\text { Proteínas } \\
\text { (g/100 g) }\end{array}$} & M. de Bôer & $21,05^{A b} \pm 0,53$ & $22,69^{\mathrm{Aa}} \pm 0,20$ & $20,01^{\mathrm{Ab}} \pm 0,75$ & $19,87^{A b} \pm 1,14$ & $20,57^{\mathrm{Ab}} \pm 0,78$ \\
\hline & SRD & $19,53^{\mathrm{Ba}} \pm 0,24$ & $20,25^{\mathrm{Ba}} \pm 0,80$ & $20,07^{A a} \pm 0,88$ & $19,28^{\mathrm{Aa}} \pm 0,31$ & $20,36^{\mathrm{Aa}} \pm 0,31$ \\
\hline \multirow{2}{*}{$\begin{array}{l}\text { Cálcio } \\
\text { (mg/100 g) }\end{array}$} & M. de Bôer & $9,63^{\mathrm{Aa}} \pm 2,10$ & $6,09^{A b} \pm 0,28$ & $5,44^{\mathrm{Ab}} \pm 0,53$ & $7,22^{\mathrm{Aab}} \pm 1,46$ & $9,47^{\mathrm{Aa}} \pm 1,63$ \\
\hline & SRD & $7,31^{\mathrm{Aa}} \pm 1,33$ & $7,70^{A a} \pm 2,02$ & $5,86^{\mathrm{Aa}} \pm 1,22$ & $7,69^{A a} \pm 1,03$ & $7,23^{\mathrm{Aa}} \pm 1,19$ \\
\hline \multirow{2}{*}{$\begin{array}{l}\text { Ferro } \\
(\mathrm{mg} / 100 \mathrm{~g})\end{array}$} & M. de Bôer & $2,81^{\mathrm{Bb}} \pm 0,05$ & $6,21^{\mathrm{Aa}} \pm 0,68$ & $8,17^{A a} \pm 2,16$ & $6,44^{\mathrm{Aa}} \pm 2,31$ & $6,67^{\mathrm{Aa}} \pm 2,55$ \\
\hline & SRD & $10,96^{\mathrm{Aa}} \pm 4,85$ & $8,64^{\mathrm{Aa}} \pm 1,33$ & $5,86^{\mathrm{Ab}} \pm 1,22$ & $10,88^{\mathrm{Aa}} \pm 4,05$ & $8,95^{\mathrm{Aa}} \pm 2,99$ \\
\hline \multirow{2}{*}{$\begin{array}{l}\text { Fósforo } \\
\text { (mg/100 g) }\end{array}$} & M. de Bôer & $146,30^{\mathrm{Ab}} \pm 32,13$ & $190,84^{\mathrm{A} a} \pm 13,45$ & $182,53^{\mathrm{Aa}} \pm 4,28$ & $186,90^{\mathrm{Ba}} \pm 18,57$ & $188,90^{\mathrm{Ba}} \pm 28,65$ \\
\hline & SRD & $141,32^{\mathrm{Ad}} \pm 7,07$ & $165,55^{\mathrm{Acd}} \pm 15,98$ & $205,75^{\mathrm{Abc}} \pm 13,35$ & $239,42^{\mathrm{Aab}} \pm 25,18$ & $271,50^{\mathrm{Aa}} \pm 13,79$ \\
\hline \multirow{2}{*}{$\begin{array}{l}\text { Colesterol } \\
(\mathrm{mg} / 100 \mathrm{~g})\end{array}$} & M. de Bôer & $53,35^{\mathrm{Bb}} \pm 1,89$ & $57,99^{\mathrm{Bb}} \pm 0,57$ & $64,48^{\mathrm{Aab}} \pm 0,95$ & $76,24^{\mathrm{Aa}} \pm 6,85$ & $77,47^{\mathrm{Ba}} \pm 5,50$ \\
\hline & SRD & $84,04^{\mathrm{Aa}} \pm 1,40$ & $82,80^{\mathrm{Aa}} \pm 5,87$ & $69,89^{\mathrm{Ab}} \pm 1,83$ & $85,84^{\mathrm{A} a} \pm 4,66$ & $89,80^{\mathrm{Aa}} \pm 6,96$ \\
\hline
\end{tabular}

(1) Os dados referem-se à média \pm desvio padrão da análise de cinco cortes comerciais de dois genótipos analisados

Médias seguidas das mesmas letras sobrescritas, maiúsculas nas colunas e minúsculas nas linhas, não diferem significativamente pelo teste de Tukey a $5 \%$ de probabilidade 
de água durante o cozimento e maior suculência. O maior valor de $\mathrm{pH}$ pode ter ocorrido em decorrência de uma quantidade baixa de glicogênio neste músculo dos animais no abate. Valores de $\mathrm{pH}$ semelhantes à faixa encontrada na presente pesquisa foram reportados por MOURA [26] em caprinos SRD.

O teor de umidade para o mestiço de Bôer apresentou diferença significativa $(\mathrm{p}<0,05)$ apenas para o corte perna, o qual teve maior teor de umidade e menor teor de gordura quando comparado aos demais cortes. Para o genótipo $\mathrm{SRD}$, o corte costela teve a menor umidade e o maior teor de gordura em relação aos outros quatro músculos. LAWRIE [15] reportou uma relação inversa entre os teores de umidade e gordura, os quais afetam diretamente as características sensoriais de "suculência" das carnes em geral. Comparando-se os dados obtidos nesta pesquisa com a literatura, verifica-se que os teores de umidade estão de acordo com MOURA [26] para caprinos SRD.

Os cortes perna (2,52 g/100 g) e lombo (7,52 g/100 g) do genótipo mestiço de Bôer apresentaram teores lipídicos significativamente diferentes $(\mathrm{p}<0,05)$, fato este justificável pela utilização do músculo na vida do animal, os músculos do lombo são menos solicitados quando comparado com os da perna. Considerando o genótipo SRD, os cortes avaliados não apresentaram diferenças significativas entre os mesmos para as gorduras, diferenças estas justificadas pelo alto desvio padrão observado entre as amostras. Embora não tenha sido observada diferença significativa no teor de lipídeos entre os genótipos estudados, os cortes de caprinos mestiços (F1 - Bôer x SRD) tenderam a apresentar concentrações de lipídeos mais elevadas quando comparados aos cortes de caprinos SRD. Estes resultados podem ser atribuídos às características próprias de cada genótipo, uma vez que ambos foram criados sob as mesmas condições em regime de confinamento. Uma observação mais precisa sobre a influência dos fatores corte e genótipo nos parâmetros químicos seria possível caso o número de repetições (animais) fosse maior. Mais uma vez foi comprovada a qualidade nutricional da carne caprina, no que se refere aos baixos percentuais de gordura apresentados pela mesma.

Apesar da influência significativa do genótipo e dos cortes nos teores protéicos analisados, observou-se que os valores para os diferentes cortes de cada genótipo apresentaram-se aproximados. O mesmo comportamento foi relatado por BRITO [9], em que foram observados teores de proteínas semelhantes nos genótipos estudados. Estes valores estão de acordo com os dados relatados para a carne caprina de animais do Nordeste do Brasil [7, 19, 27].

Avaliando-se o conteúdo de cálcio no tecido muscular dos cortes do mestiço de Bôer, observou-se que o corte lombo foi o que apresentou menor concentração $(5,44 \mathrm{mg} / 100 \mathrm{~g})$ e o corte paleta a maior concentração (9,63 mg/100 g). Em relação ao caprino SRD, semelhante ao mestiço de Bôer, o corte lombo apresentou tendência ao menor conteúdo de cálcio (5,86 mg/100 g). No entanto, as maiores concentrações foram nos cortes perna $(7,70 \mathrm{mg} / 100 \mathrm{~g})$ e costela (7,69 mg/100 g). Os valores encontrados estão de acordo com os dados obtidos por MONTE [25]. Por outro lado, os valores citados por ARRUDA [3] para animais Crioulo foram inferiores aos reportados neste estudo.

Os teores de ferro para os caprinos mestiços de Bôer variaram de 2,81 mg/100 g (paleta) a 8,17 mg/100 g (lombo). De forma inversa, nos cortes do genótipo SRD, os teores de ferro variaram de 5,86 mg/100 g para o corte lombo e de $10,96 \mathrm{mg} / 100 \mathrm{~g}$ para o corte paleta. Estes resultados apresentam-se bem acima dos valores reportados por MADRUGA et al. [19] e ARRUDA [3], que relataram valores médios de ferro de 2,35 e 2,29 mg/100 g, respectivamente. Os teores de ferro encontrados nas amostras da carne dos genótipos estudados confirmam a afirmação de que a carne caprina é uma fonte valiosa de ferro [15].

Com relação aos teores de fósforo, a maior concentração foi encontrada no corte pescoço dos caprinos SRD $(271,50 \mathrm{mg} / 100 \mathrm{~g})$, sendo que o menor teor foi encontrado para o corte paleta dos genótipos SRD (141, 32 mg/100 g) e mestiço de Bôer (146,30 mg/100 g). Os valores relatados neste trabalho encontram-se ligeiramente acima da média reportada por BESERRA et al. [7], que obtiveram valores médios variando de 147,60 a 161, $82 \mathrm{mg} / 100 \mathrm{~g}$ no tecido muscular de caprinos SRD. Os valores apresentados por ARRUDA [3] e MADRUGA et al. [22] também foram inferiores quando comparados com os dados obtidos neste estudo.

Na literatura pesquisada, não foi encontrada razão para tais variações, uma vez que minerais em carnes têm sido reportadas como componentes com poucas variações [15].

Os teores de colesterol encontrados revelaram que a carne de caprinos SRD apresentou maior teor que a de caprinos de mestiços de Bôer. Com relação aos caprinos SRD, o corte lombo apresentou menor teor de colesterol (69,89 mg/100 g), enquanto os cortes costela $(85,84 \mathrm{mg} / 100 \mathrm{~g})$ e pescoço $(89,80 \mathrm{mg} / 100 \mathrm{~g})$ detiveram os maiores percentuais. Da mesma forma, o maior teor de colesterol, para o genótipo mestiço de Bôer, foi detectado nos cortes costela $(76,24 \mathrm{mg} / 100 \mathrm{~g})$ e pescoço (77,47 mg/100 g). Entretanto, os caprinos mestiços de Bôer detiveram um menor teor de colesterol para o corte paleta (53,35 mg/100 g). Resultados semelhantes de teores de colesterol foram encontrados em carne de caprinos mestiços do brejo paraibano, confirmando-se mais uma vez a qualidade nutricional da carne caprina [20, 22, 23, 35]. Não se tendo observado nenhuma relação entre os teores de gordura e colesterol, associado às baixas concentrações de gordura e colesterol, recomenda-se o consumo da carne caprina independentemente do corte comercial.

Dos oito atributos sensoriais (aparência, odor caprino, odor de carne assada, textura, maciez, sabor, suculência e qualidade total da carne caprina) analisados, os provadores observaram diferença significativa apenas em três destes - odor caprino, odor de carne assada e textura (Tabela 2). Os dados da análise de variância mostraram que o odor caprino foi influenciado apenas pelo genótipo, sendo que os atributos de odor de carne assada e textura sofreram influência do fator corte, não sendo observada interação 
TABELA 2. Características sensoriais de três cortes comerciais da carne de caprinos SRD e mestiço (F1 - SRD x Bôer) (1)

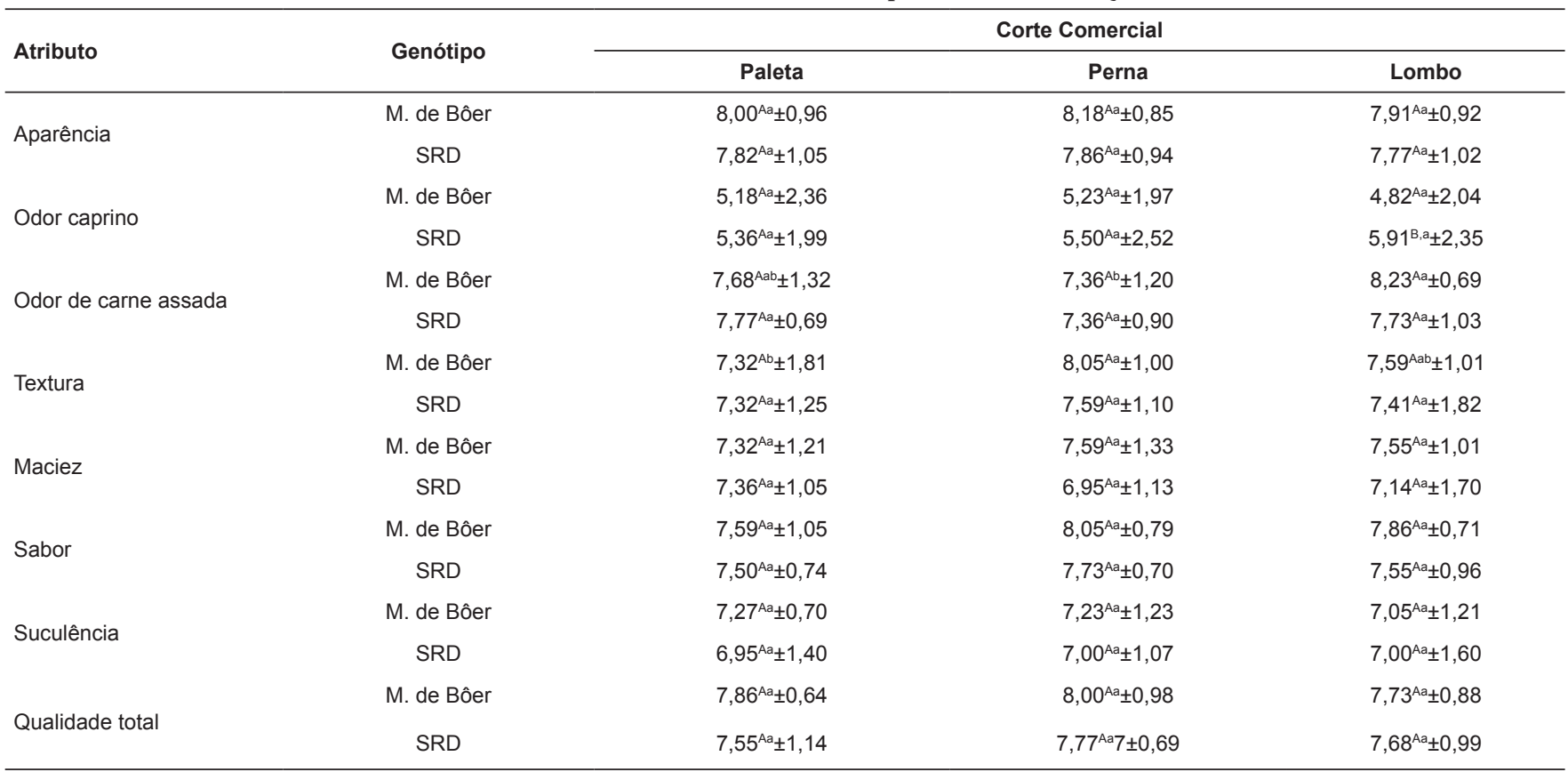

(1) Os dados referem-se à média \pm desvio padrão da análise de três cortes comerciais de dois genótipos analisados

Médias seguidas das mesmas letras sobrescritas, maiúsculas nas colunas e minúsculas nas linhas, não diferem significativamente pelo teste de Tukey a $5 \%$ de probabilidade

entre estes fatores para nenhum dos oito atributos sensoriais avaliados.

No corte lombo do genótipo SRD evidenciou-se um odor caprino mais intenso em comparação ao do mesmo músculo do mestiço (F1 - Bôer x SRD). Acredita-se que a carne caprina de animal macho adulto apresenta um aroma forte e desagradável, caracterizado como odor "caprino". Porém, evidências científicas que justifiquem esse aroma são ainda pouco claras. HA e LINDSAY [11] relacionaram este aroma com os componentes fenólicos isolados do tecido adiposo da carne caprina. ROUSSET-AKRIM et al. [30] e YOUNG et al. [36] constataram que os ácidos graxos de cadeia média ( 7 a 10 carbonos), os ácidos graxos ramificados e 3-metil indol seriam os componentes químicos responsáveis por três descritores sensoriais de aroma e sabor da carne cozida de ovinos - "odor ovino", "rancidez", "sabor de carne ovina". MADRUGA [17] reportou que o perfil aromático de mestiços de Moxotó e SRD apresentou maior formação de compostos aromáticos em comparação aos mestiços de Bôer e SRD, indicando o valor aromático dos animais nativos. Enfatiza-se que pesquisas se fazem necessárias para um melhor conhecimento dos componentes-chave, os quais são responsáveis pela formação do aroma característico da carne caprina.

As notas atribuídas à maioria dos atributos avaliados com relação aos cortes de cada genótipo apresentaram-se de forma semelhante. Entretanto, observa-se a influência dos cortes do genótipo mestiço (F1 - SRD x Bôer), nos atributos de odor de carne assada e textura. As notas atribuídas pelos provadores ao atributo odor de carne assada apresentou pontuação que variou de 8,23 (muito agradável) para o corte lombo a 7,36 (regularmente agradável) para o corte perna. É interessante ressaltar que o aroma de carne assada foi mais intenso no corte que apresentou maior teor de gordura, confirmando-se a importância da gordura na formação do aroma cárneo.

Analisando-se o atributo textura, verificou-se uma diferença significativa $(\mathrm{p}<0,05)$ entre os cortes paleta e perna para o genótipo mestiço (F1 - SRD x Bôer). O corte paleta recebeu uma pontuação média de 7,32 correspondendo a uma carne de textura moderadamente firme. O corte perna apresentou a textura estatisticamente diferente, recebendo a maior pontuação com valor de 8,05 correspondendo a uma carne muito firme, tendo apresentado maior teor de umidade e menor teor de gordura.

Dentre os trabalhos realizados sobre os atributos de qualidade sensorial de carne caprina, poucos têm citado a influência do genótipo e dos cortes comerciais. ZAPATA et al. [37] relataram que na aceitação de carnes provenientes de diferentes genótipos ou sistema de alimentação não foram encontradas diferenças significativas entre os atributos sensoriais. MARSHALL [24] enfatizou que o mercado internacional passou da comercialização de carcaças para a de cortes ou partes destes. Segundo este autor, exemplo dessa tendência foi o que ocorreu na Nova Zelândia que, nos anos 80 , tinha mais de $70 \%$ da carne de cordeiro exportada na forma de carcaça sendo que, atualmente, estes índices estão reduzidos a $10 \% \mathrm{e}$ continuam diminuindo, sugerindo a importância do conhecimento científico das propriedades químicas e sensoriais dos cortes de carne oferecidos ao consumidor.

\section{4 - CONCLUSÕES}

Nas condições experimentais, os parâmetros genótipos e cortes comerciais influenciaram de forma significativa 
a composição química da carne caprina; no entanto, os atributos sensoriais sofreram pouca influência destes fatores, observando-se uma tendência pela preferência, por parte dos provadores, pela carne de caprinos mestiços de Bôer. A carne caprina, seja de animais mestiços de Bôer ou de animais SRD, apresentou-se como alimento de excelente valor nutricional, com baixos teores de gordura e elevados percentuais protéicos, associados às excelentes características sensoriais.

\section{5 - REFERÊNCIAS BIBLIOGRÁFICAS}

[1] AMARINE, M.A.; PANGBORN, M.R.; ROESSLER, E.B. Principles of Sensory Evaluation of Food. New York: Academic Press, 1965, 602 p.

[2] AOAC. Association of Official Analytical Chemists. 2000. Official Methods of Analysis. Washington: AOAC. $1018 \mathrm{p}$.

[3] ARRUDA, S.G.B. Influência da Idade de Abate e da Castração na Composição Química, Físico-química e Sensorial de Lingüiça Caprina Tipo Frescal. João Pessoa, 1999. 108 p. Dissertação (Mestre em Ciência e Tecnologia de Alimentos), Departamento de Tecnologia Química e de Alimentos, Universidade Federal da Paraíba (UFPB).

[4] BATISTA, A.S.M. Aproveitamento de Carne Caprina de Descarte na Forma de Embutido Cru Tipo Hambúrguer. Fortaleza, 1999, 74 p. Dissertação (Mestre em Tecnologia de Alimentos), Departamento de Tecnologia de Alimentos, Universidade Federal do Ceará (UFC).

[5] BESERRA, F.J; MELO, L.R.R; RODRIGUES, M.C.P; SILVA, E.M.C; NASSU, R.T. Desenvolvimento e caracterização físico-química e sensorial de embutido cozido tipo apresuntado de carne de caprino. Ciência Rural, v. 33, n. 6, p. 1141-1147, 2003.

[6] BESERRA, F.J; MONTE, A.L.S; BEZERRA, L.C.N.M; NASSU, R.T. Caracterização química da carne de cabrito da raça Moxotó e de cruzas Pardo Alpina $\mathrm{x}$ Moxotó. Pesquisa Agropecuária Brasileira, v. 35, n. 1, p. 243-253, 2000.

[7] BESERRA, F.J; MOURA, R.P; SILVA, E.M.C; MADRUGA, M.S. Características físicas e físico-químicas da carne de caprinos SRD com diferentes pesos de abate. Revista Tecnologia da Carne, v. 3, n. 2, p. 1-6, 2001.

[8] BOHAC, C.E.; RHEE, K.S.; ONO, K. Assessment of methodologies for colorimetric cholesterol assay of meats. Journal of Food Science, v. 53, p. 1642-1693, 1988.

[9] BRITO, E.A. Desempenho e Características de Carcaças de Caprinos e Ovinos Terminados em Confinamento. Areia, 2002. 93 p. Dissertação (Mestre em Zootecnia), Departamento de Zootecnia, Universidade Federal da Paraíba (UFPB).

[10] FOLCH, J.; LESS, M.; STANLEY, S.A simple method for the isolation and purification of total lipids from animal tissues. Journal of Biological Chemistry, v. 226, p. 497-509, 1957.

[11] HA, J.K.; LINDSAY, R.C. Volatile alkylphenol in species related characterising flavors of red meats. Journal of Food Science, v. 56, n. 5, p. 1197-1202, 1991.

[12] IBGE. Pesquisa Pecuária Municipal. Sistema IBGE de
Recuperação Automática-SIDRA. www.sidra.ibge.gov. br, 2003.

[13] INSTITUTO ADOLFO LUTZ. Normas Analíticas. Métodos Químicos e Físicos para Análises de Alimentos. São Paulo: IAL. 1985, 533 p.

[14] LARMOND, E. Laboratory Methods for Evaluation of Foods. Ottawa: Food Research Institute. Canada Department of Agriculture, 1979.

[15] LAWRIE, R.A. Meat Science. $4^{\text {th }}$ ed. Oxford: Pergamon Press, 1985. 267 p.

[16] MADRUGA, M.S. Carne Ovina e Caprina: Saborosa e Suculenta. In: REUNIÃO TÉCNICA CIENTÍFICA EM OVINOCAPRINOCULTURA, 1, 2004, Itapetinga. Palestra... Itapetinga: UESB-Ba, 2004a.

[17] MADRUGA, M.S. Processamento e Características Físicas e Organolépticas das Carnes Caprina e Ovina. In: IV SEMANA DA CAPRINOCULTURA E OVINOCULTURA BRASILEIRA, 1, 2004, Embrapa Caprinos. Anais de Palestra... Sobral: Embrapa Caprinos-Ce, 2004b.

[18] MADRUGA, M.S. Fatores que Afetam a Qualidade da Carne Caprina e Ovina. In: $2^{\circ}$. SINCORTE-SIMPÓSIO INTERNACIONAL DE CAPRINOS E OVINOS DE CORTE, 2, 2003, João Pessoa. Anais de Palestra... João Pessoa: EMEPA, p. 417-432, 29 de setembro a 03 de outubro de 2003.

[19] MADRUGA, M.S. Artigo Técnico - Carne Caprina: Verdades e mitos à luz da ciência. Revista Nacional da Carne, v. 23, n. 264, p. 34-40, 1999.

[20] MADRUGA, M.S.; ARRUDA, S.G.B.; NARAIN, N.; SOUZA, J.G. Castration and slaughter age effects on fat components of the "mestiço" goat meat. Small Ruminant Research, v. 42, p. 77-82, 2001.

[21] MADRUGA, M.S.; ARRUDA, S.G.B.; NARAIN, N.; SOUZA, J.G. Castration and slaughter age effects on panel assessment and aroma compounds of the "mestiço" goat meat. Meat Science, v. 56, p. 117-125, 2000.

[22] MADRUGA, M.S.; ARRUDA, S.G.B.; NASCIMENTOS, J.A. Castration and slaughter age effects on nutritive value of the "mestiço" goat meat. Meat Science, v. 52, n. 2, p. 119-125, 1999.

[23] MADRUGA, M.S.; NARAIN, N.; ARRUDA, S.G.B.; SOUZA, J.G.; COSTA, R.G.; BESERRA, F.J. Influência da idade de abate e da castração nas qualidades físico-químicas, sensoriais e aromáticas da carne caprina. Revista Brasileira de Zootecnia, v. 31, n. 3, p. 1562-1570, 2002.

[24] MARSHALL, A. Producción de cordero em Nueva Zelanda: Enfoque de mercado conducido por la producción e la tecnología. $1^{\circ}$. Simposium Internacional de ovinos de carne. Pachinca (Hidalgo) México, 17 al 18 de noviembre, p.8-32, 2002

[25] MONTE, A.L.S. Caracterização Centesimal e da Fração Mineral da Carne de Cabrito Mamão da Raça Moxotó e Cruzas Pardo-Alpina x Moxotó. Fortaleza, 1996. 64 p. Dissertação (Mestre em Tecnologia de Alimentos), Departamento de Tecnologia de Alimentos, Universidade Federal do Ceará (UFC).

[26] MOURA, R.P. Características Químicas e FísicoQuímicas da Carne de Caprinos SRD Analisados em Diferentes Pesos de Abate. Fortaleza, 1998, 77 p. Dissertação (Mestre em Tecnologia de Alimentos), Departamento de Tecnologia de Alimentos, Universidade Federal do Ceará (UFC). 
[27] NASSU, R.T; BESERRA, F.J.; SOUSA, M.P.; FREITAS, A.N.M. Comparação entre características químicas de carne de caprinos do Nordeste brasileiro, abatidos em diferentes idades. Revista Agropecuária Brasileira, v. 64, p. 1-4, 2002.

[28] PIMENTEL, F.G. Curso de Estatística Experimental. $11^{\mathrm{a}}$ ed. São Paulo: Nobel, 1985. $466 \mathrm{p}$.

[29] RANGANNA, S. Handbook of Analysis and Quality Control for Fruits and Vegetable Products. New Delhi: McGraw-Hill, 1991. $1112 \mathrm{p}$.

[30] ROUSSEL-AKIM, S.; YOUNG, O.A.; BERDAGUÉ. Diet and growth in panel assessment of sheep meat odour and flavour. Meat Science, v. 45, n. 2, p. 169-181, 1997

[31] SANTANA, O.P.; SIMPLICIO, A. Goat production in Brazil. In: LOKESHWAR, R. R. (Ed.). Recent Advances in Goat Production. Proceedings and papers presented at V International conference on goats, New Delhi, India, 1992. p. 460-474.

[32] SAS INSTITUTE. User's Guide to Statistics. Version 6.12. Cary, USA: North Caroline State University, 1996. $956 \mathrm{p}$.

[33] SILVA SOBRINHO, A.G.; GONZAGA NETO, S. Produção de Carne Caprina e Cortes da Carcaça. Jaboticabal: FCAV, 2001. 17 p.

[34] SOUSA neto, J. Demanda Potencial de Carne de
Caprino e Ovino e Perspectivas de Oferta - 1985/1990. Sobral: Embrapa, 1987. 16 p.

[35] SOUZA, J.G. Efeito da Idade de Abate e da Castração nos Componentes Lipídicos de Caprinos Mestiços do Brejo Paraibano. João Pessoa, 1999. 65 p. Dissertação (Mestre em Ciência e Tecnologia de Alimentos), Departamento de Tecnologia Química e de Alimentos, Universidade Federal da Paraíba (UFPB).

[36] YOUNG, O.A.; BERDAGUÉ, C.V.; ROUSSET-AKRIM, S.; THERIEZ, M. Fat-borne volatiles and sheep meat odour. Meat Science, v. 45, n. 2, p. 183-200, 1997

[37] ZAPATA, J.F.F.; SEABRA, L.M.J.; NOGUEIRA, C.M.; BARROS, N.N. Estudo da qualidade da carne ovina no Nordeste brasileiro: Propriedades físicas e sensoriais. Ciência e Tecnologia de Alimentos, v. 20, n. 2, p. 274-277, 2000.

[38] ZAPATA, J.F.F.; NOGUEIRA, C.M.; SEABRA, L.M.J.; BEZERRA, L.C.N.M.; BESERRA, F.J. Características da carne de pequenos ruminantes do Nordeste do Brasil. Bol. sbCTA, v.37, n. 2, p.146-153, 2003.

\section{6 - AGRADECIMENTOS}

Os autores agradecem ao CNPq e à CAPES pelo apoio financeiro e pelas bolsas concedidas. À Emepa-PB pelo fornecimento do material analisado. Aos professores e alunos do PPGCTA-UFPB, pela colaboração nas análises sensoriais. 